\title{
Microfabricated Actuators and Their Application to Optics
}

\author{
Jeffry J. Sniegowski and Ernest J. Garcia . \\ Sandia National Laboratories, Albuquerque, NM 87185
}

\begin{abstract}
Several authors [1,2] have given overviews of microelectromechanical systems, including microactuators. In our presentation we will review some of these results, and provide a brief description of the basic principles of operation, fabrication, and application, of a few selected microactuators (electrostatic and surface tension driven).

We present a description of a three-level mechanical polysilicon surface-micromachining technology with a discussion of the advantages of this level of process complexity. This technology is capable of forming complex, batch-fabricated, interconnected, and interactive, microactuated micromechanisms which include optical elements. The inclusion of a third deposited layer of mechanical polysilicon greatly extends the degree of complexity available for micromechanism design. Two examples of microactuators fabricated using this process are provided to illustrate the capabilities and usefulness of the technology. The first actuator is an example of a novel actuation mechanism based on the effect of surface tension at these micro-scale dimensions and of a microstructure within a microstructure. The second is a comb-drive-based microengine which has direct application as a drive and power source for micro optical elements, specifically, micro mirrors and micro shutters. This design [3] converts linear oscillatory motion from electrostatic comb drive actuators into rotational motion via a direct linkage connection. The microengine provides output in the form of a continuously rotating output gear that is capable of delivering drive torque to a micromechanism.
\end{abstract}

Keywords: actuators, microactuators, microengines, micromotors, surface micromachining, polysilicon, surface tension, optical actuators, microelectromechanical systems, electrostatic actuators

\section{INTRODUCTION}

MicroElectroMechanical systems (MEMS) afford us the opportunity to perform functions in the micromechanical world analogous to functions now performed by microelectronic devices in the electronics arena. An often cited motivation for developing MEMS is the potential extension to the advantages of small scale, which are currently available in electronic devices, to mechanical systems with moving parts. Several aspects of the advantages of MEMS, namely that micromechanical devices and systems are inherently smaller, lighter, faster, and possibly, more precise than their macro counterparts, have been discussed elsewhere [1]. In addition, the ability to integrate microelectronics with micromechanical devices will permit the development of systems that perform functions previously deemed impossible. The fundamental building blocks of many systems consist of three basic functions: sensing, decision making, and actuation. The role of actuation is a critical part of most systems and will most certainly be required for nearly any type of micro machinery, hence our interest in microactuators. Unfortunately, 


\section{DISCLAIMER}

Portions of this document may be illegible in electronic image products. Images are produced from the best available original document. 
microactuation elements have thus far lagged in development compared to microsensor capabilities. This is principally due to the greater degree of mechanical complexity of the actuator elements and the additional issues of wear and friction.

The mechanism of electrostatic actuation is particularly important with regards to surface micromachining processes. Surface micromachining lends itself to the fabrication of electrostatic structures, thus, it is useful to review the principle of operation. Because the electrostatic actuator is of such predominance, we will discuss the basic operating principles of two generic types of electrostatic actuators in Section 2. The surface tension actuator works on a completely different principle than electrostatic actuators, but it is also compatible with the standard Integrated Circuit (IC)-type surface micromachining processes and will be discussed in Section 5.1.

Section 3 provides examples of optical functions that can benefit by the use of microactuators. Sections 4 and 5 will discuss fabrication aspects and specific actuators that we are developing for use in optical systems, and we will conclude our discussion in Section 6.

\section{MICROACTUATION FUNDAMENTALS}

There are several ways of organizing a discussion on micromechanics and microactuation. One is to draw distinctions by the means, or technique, of fabrication, e.g., polysilicon surface micromachining [4], silicon bulk micromachining [5], LIGA or LIGA-like micromachining [6], and others. A second approach would be by distinction of the mechanism of actuation, for example, electrostatic, electromagnetic and magnetic, piezoelectric, shape memory alloy (SMA), thermoelectromechanical, to name a few. Unfortunately, neither of these provides a completely clean categorization. Generally, however, we can say that electrostatic-based actuators are most easily fabricated by batch methods with IC-type processes, while also being the most easily integrated with IC control. The other forms of actuation may be "better", i.e., greater force and/or displacement, however, they tend to require more specialized processing and are not as easily integrated into IC-type processing principally due to material compatibility issues. We have chosen to discuss electrostatic actuation fundamentals to set the stage for our subsequent discussion of specific devices which utilize surface micromachined electrostatic actuators.

An actuator in this discussion is defined as an element which applies a force to some object through a distance. From basic mechanics, an actuator performs work, as it moves from point a to point $b$, as given by eqn. (1),

$$
W=\int_{a}^{b} F \cdot d \underset{\sim}{x}
$$

where $\underset{\sim}{\mathrm{F}}$ is the force vector and $\underset{\sim}{\mathrm{X}}$ is the displacement vector. We can assume, in general, that the more work an actuator can perform, the more useful this actuator will be for specific applications. This immediately leads to the concept of rate of work or power defined by eqn. (2), 


$$
P=F \cdot \mathrm{V}
$$

where $\underset{\sim}{\mathrm{V}}$ is the velocity at the point of application of $\underset{\sim}{\mathrm{F}}$. Power can also be expressed in terms of torque $\underset{\sim}{\mathrm{T}}$ and angular velocity $\underset{\sim}{\omega}$ as in eqn. (3).

$$
P=\underline{T} \cdot \stackrel{\omega}{\sim}
$$

It is obvious that we would like for our actuators to provide large forces, through large displacements, and at high power. The amount of force, displacement, or power available will depend on the type of actuator used. For example, there are actuators that are capable of delivering large forces but only through very limited displacements. Piezoelectric actuators tend to exhibit this type of characteristic [7]. Conversely, there are actuators that can move through large displacements but are only capable of delivering small forces. An electrostatic micromotor is an example of that type of actuator [8]. A more thorough review and comparison of microactuation can be found in the work by Fujita and Gabriel [9], while references to early work with micromechanics and optics can be found in the work of Jaecklin, et. al., [10]. Fujita and Gabriel provide a table of comparison for various mechanisms for actuation at the micro scale.

\subsection{Parallel Plate Electrostatic Actuation}

If we start with a basic configuration for two conductive plates, such as that given in Fig. 1, we can develop some fundamental relationships for force, displacement, and energy that will be useful for our discussion of electrostatic actuators.

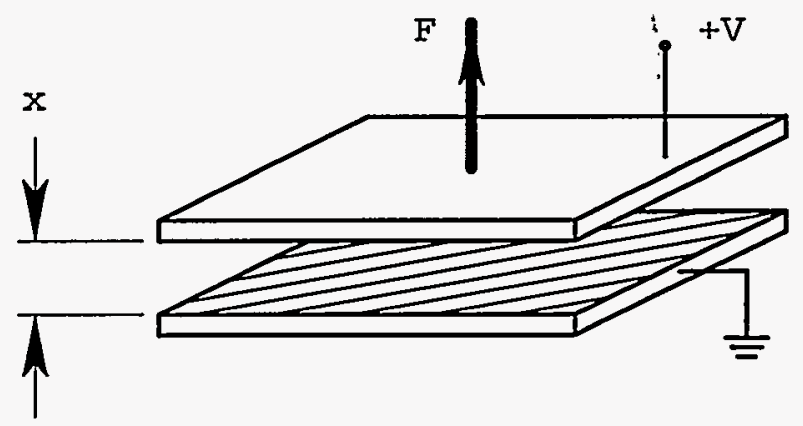

Fig. 1 Capacitive Plate as an Actuator

Assume the lower plate in Fig. 1 is fixed in place and referenced to ground and the upper plate is connected to a constant potential $\mathrm{V}$. The two plates each have area $\mathrm{A}$, and are separated by a distance $\mathrm{x}$, called the gap. $\mathrm{A}$ force $\mathrm{F}$ holds the upper plate in the equilibrium position shown. Effects due to fringing fields will be neglected. The dielectric material between the plates has a dielectric constant $\varepsilon=\varepsilon_{\mathrm{r}} \varepsilon_{0}$, where $\varepsilon_{\mathrm{r}}$ is the relative dielectric constant, and $\varepsilon_{0}$ is the permittivity of free space $\left(8.85 \times 10^{-12}[\mathrm{~F} / \mathrm{m}]\right)$. Note that for air $\varepsilon_{\mathrm{r}} \approx 1$. 
To obtain an expression for the equilibrium force acting on the top plate, we will use the principle of virtual work. The stored potential energy in the electric field is given by eqn. (4). (Note that $V$ with a subscript refers to energy and $\mathrm{V}$ without a subscript is a voltage)

$$
V_{s e c}=\frac{1}{2} C V^{2}
$$

In order to maintain a constant voltage $\mathrm{V}$, the energy contribution due to the external energy source (battery) is,

$$
V_{\text {extrent }}=-\int_{0}^{1} V I(t) d t=-V Q=-C V^{2}
$$

giving a total potential energy for the system of,

$$
V_{\text {pat }}=V_{\text {set }}+V_{\text {catmat }}=-\frac{1}{2} C V^{2}
$$

For the system in Fig. 1, the capacitance $\mathrm{C}$ is,

$$
C=\frac{\varepsilon A}{x}
$$

The expression for total potential energy is then,

$$
V_{p a t}=-\frac{1}{2} \frac{\varepsilon A}{x} V^{2}
$$

Eqn. (9) is the expression for the principle of virtual work.

$$
\delta W=0
$$

Eqn. (10) is the expression for virtual work with $\delta x$ equal to a virtual displacement.

$$
\delta W=F \delta x-\delta V_{p o t}
$$

Substitution of eqn. (8) into eqn. (10) yields,

$$
\delta W=F \delta x-\delta\left(-\frac{1}{2} \frac{\varepsilon A}{x} V^{2}\right)
$$

Substitution of eqn. (11) into eqn. (9) results in eqn. (12) which can be solved for F.

$$
0=\left[F-\frac{1}{2} \frac{\varepsilon A}{x^{2}} V^{2}\right] \delta x
$$

The final expression for the force required to keep the system in equilibrium is,

$$
F=\frac{1}{2} \frac{\varepsilon A}{x^{2}} V^{2}
$$

It is interesting to now examine the forces obtained from eqn. (13) for devices of varying sizes. First we will rearrange eqn. (13) by dividing both sides by the area $A$ of the capacitor plates and defining F/A as the electrostatic pressure $\mathrm{p}$, given by eqn (14). 


$$
p=\frac{1}{2} \frac{\varepsilon}{x^{2}} V^{2}
$$

Fig. 2 is a plot of eqn. (14) assuming $\varepsilon_{\mathrm{r}}=1$ and $V=30 \mathrm{~V}$.

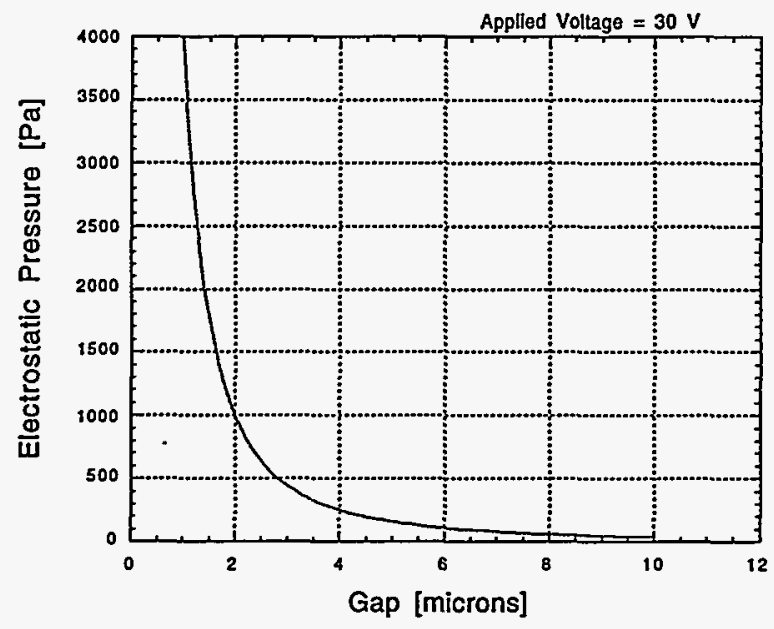

Fig. 2 Electrostatic Pressure for Parallel Plate Capacitor

Fig. 2 readily illustrates the $\left(1 / \mathrm{x}^{2}\right)$ drop in electrostatic pressure. Electrostatic actuators are obviously most effective when their gap dimensions are relatively small. For an actuator that is 50 microns by 50 microns square, with a 2 micron gap, the force obtained is $2.5 \mu \mathrm{N}$ at $30 \mathrm{~V}$. Note that if we include the effects of fringing fields in our analysis, the force calculated will be greater than that given by eqn. (13).

\subsection{Comb-Drive Electrostatic Actuation}

An obvious drawback to the parallel plate capacitor, as an actuator, is the rapidity with which the force it exerts drops off with increasing gap. Another type of electrostatic actuator, due to Tang and Howe, known as a comb-drive actuator [11], eliminates this difficulty.

The derivation for the electrostatic comb-drive force relationship begins in the same manner as does the parallel plate capacitor derivation. Fig. 3 shows the geometry of a "comb-drive" actuator with thickness t into the plane of the drawing. As before, we assume the lower element is fixed in place and held at ground potential, while the upper element is held at fixed voltage $\mathrm{V}$, and is kept in equilibrium by the force $\mathrm{F}$. Using the same procedure as before we write expressions for the electric field potential energy and the contribution due to the external energy source required to keep the applied voltage constant. Again, we neglect fringing fields. 


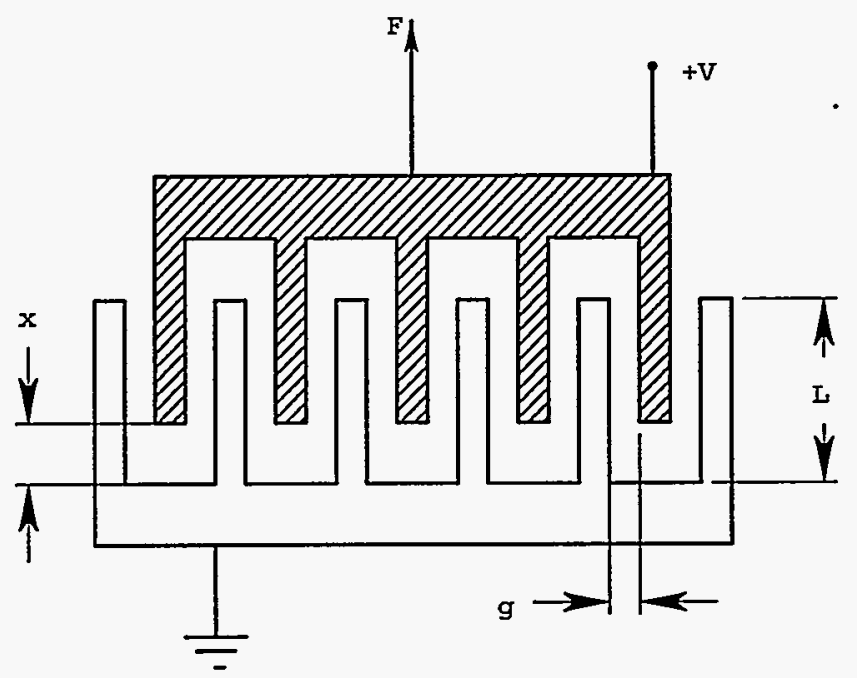

Fig. 3 Comb-drive Actuator Schematic

The stored energy in the electric field is,

$$
V_{\text {put }}=\frac{1}{2} C V^{2}
$$

In order to maintain a constant voltage $\mathrm{V}$, the energy contribution due to the external energy source (battery) is,

$$
V_{\text {anroud }}=-\int_{0}^{1} V I(t) d t=-V Q=-C V^{2}
$$

giving a total potential energy for the system of,

$$
V_{p e x}=V_{s e t}+V_{\text {extred }}=-\frac{1}{2} C V^{2}
$$

For the system in Fig. 3, the capacitance $\mathrm{C}$ takes on a different form. The capacitance for a single tooth face across the gap $\mathrm{g}$ is,

$$
C_{\text {single }}=\frac{\varepsilon A}{g}
$$

with the area $\mathrm{A}$ given by eqn.(19).

$$
A=t(L-x)
$$

The capacitance is then expressed as,

$$
C_{\text {single }}=\frac{\varepsilon t(L-x)}{g}
$$

Each tooth has two sides, therefore, each tooth has two capacitors. If we have $n$ teeth on our upper actuator, we have $2 \mathrm{n}$ capacitors and hence the total capacitance is,

$$
C=2 n \frac{\varepsilon t(L-x)}{g}
$$


where all other contributions to capacitance have been ignored.

The expression for virtual work, eqn. (10), is repeated below.

$$
\delta W=F \delta x-\delta V_{\text {pot }}
$$

Using eqns. (17) and (21) we substitute into eqn. (22) and by the principle of virtual work set eqn. (22) equal to zero.

$$
\delta W=F \delta x-\delta\left(-n \frac{\varepsilon t(L-x)}{g} V^{2}\right)=0
$$

Eqn. (23) then becomes,

$$
0=\left[F-n \varepsilon \frac{t}{g} V^{2}\right] \delta x
$$

which is readily solved for the equilibrium force $F$.

$$
F=n \varepsilon \frac{t}{g} V^{2}
$$

Eqn. (25) can now be compared directly with eqn. (13). The force for a parallel plate capacitor varies as $\left(1 / \mathrm{x}^{2}\right)$, while the force for the comb-drive device is constant for any value of $\mathrm{x}$ as long as the comb fingers are reasonably engaged [12]. This fact is extremely important and allows much more latitude in designing actuators.

Fringing fields for comb-drive actuators also give rise to forces out of the plane which can result in levitation of the actuator away from the substrate [13]. In addition, there will be a lateral instability depending on how the actuator is supported, i.e., if the lateral stiffness is insufficient, the upper actuator will be attracted sideways and the upper actuator teeth will stick to the fixed teeth. The suspension shown in Figure 4a (or in reference [11]) is stiff in the lateral direction and compliant in the intended direction of motion.

\section{MICROACTUATION AND OPTICS EXAMPLES}

Table 1 is introduced as a reference list of examples of possible functions performed by microactuators as appropriate to optics. One optical element which has seen considerable attention with regards to the need for microactuation is an optical switch $[7,14,15,16,17]$. A principle area of application for an optical switch is high speed optical data communication networks $[15,16]$. The switch's function is to bypass devices connected to the network without disrupting operation of the network. There are several methods of accomplishing the switching operation which have been attempted on the micro-scale. Integrated optical waveguide switches which utilize the electrostatic deformation of a micromechanical beam or cantilever have been fabricated [14,18,24]. These are prime examples of basic electromechanical elements actuated by electrostatic forces. A second switching principle is to simply physically move and align an initial fiber to one or more alternate fibers. This approach has typically made use of the

electrostatic force $[19,20]$, but other means of microactuation such as SMA [19,22] and magnetic means [21] have been tried. A final example for optical microactuated switching is the use of physically positioned mirrors which re- 
direct the optical path between stationary fibers [16]. In this particular example, the actuation mechanism is the electrostatic comb-drive and the actuator, mirror, and lens are formed by the LIGA process. In any of these approaches, it is desirable to produce, at a low cost, small, effective switches, which are easily embedded in the optical network - all of which are potential strengths of batch-fabricated, micromachining, techniques.

\begin{tabular}{|l|l|}
\hline OPTICAL FUNCTIONS & REFERENCES \\
\hline Optical switches & {$[7,14,15,16,17]$} \\
Optical waveguide couplers & {$[14]$} \\
Optical waveguide switch & {$[14,18]$} \\
Fiber handling/optical alignment/coupling & {$[19,20,21,22]$} \\
Modulation & {$[14,17,18,23,24,25,26,27,28]$} \\
Dynamic-focus mirrors & {$[29]$} \\
Interferometer & {$[30]$} \\
Scanning & {$[31,32]$} \\
Choppers & {$[7,33,34,35]$} \\
Integrated Optical elements & {$[36]$} \\
\hline
\end{tabular}

Table 1. A partial list of optical functions that lend themselves to microactuation and micromachining technology.

A second optical function which has received considerable attention from the micromachining/microactuation community is the function of spatial light modulation. Again, in many instances the choice of actuation mechanism is electrostatics. Of these, possibly the most successful has been Texas Instrument's Digital Micromirror Device (DMD) $[14,23,37]$ which has been continuously pursued for the past 2 decades.

The function of optical scanning may lend itself as a first demonstrated use of a polysilicon, surface micromachined micromotor [31,32]. This is an example of a microactuator functioning as an independent element in the device, i.e., the micromotor is a separate entity which is then coupled to the optical element. This is different from devices where the optical element is the entity which is directly actuated on by the force, e.g., direct movement of a fiber by an electrostatic force [19]. This subtle distinction leads us into the second half of this paper which is a description of a multi-level polysilicon surface micromachining technology and two types of mechanical microactuators made possible through this technology. These two actuators are examples of the independent-type microactuation.

\section{FABRICATION - POLYSILICON SURFACE MICROMACHINING}

Probably the first demonstration, almost 30 years ago, of a surface micromachined device was the Resonant Gate Transistor by Nathanson, Newell, Wickstrom, and Davis [38] which consisted of a transistor with a free-standing metal cantilever beam as the transistor gate. Several years later, but still over a dozen years ago, one of the first 
descriptions of polycrystalline silicon (polysilicon) surface micromachining was given by Howe and Muller [39]. Since then, the basic process with a single layer of mechanical polysilicon has been used to fabricate a myriad of devices. The obvious extension of the process is to multiple levels of mechanical polysilicon layers with intervening layers of sacrificial films. However, this extension is not without cost, and careful consideration of the advantages to be gained against the investment required to develop the process must be made. Earlier work by Fan, Tai and Muller [40] illustrated that mechanical elements such as fixed-axle pin joints, self-constraining pin joints, and constrained sliders can be made, and require, two layers of polysilicon. This work clearly indicated that the fabrication of movable, connected, mechanical elements are feasible with surface micromachining. However, complex, interactive mechanical devices require yet a third level of mechanical polysilicon to construct. This is easily seen by following Fig. 4.a-c.

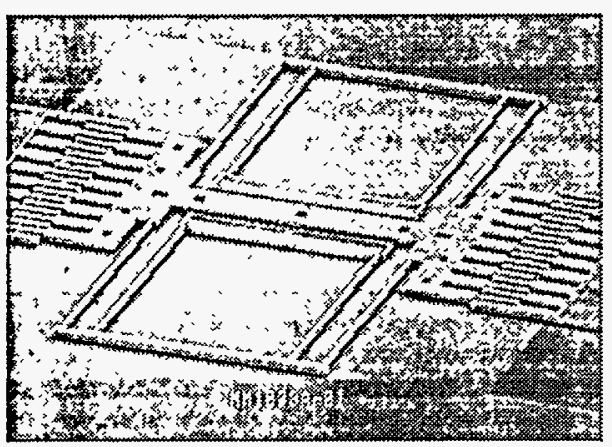

(a)

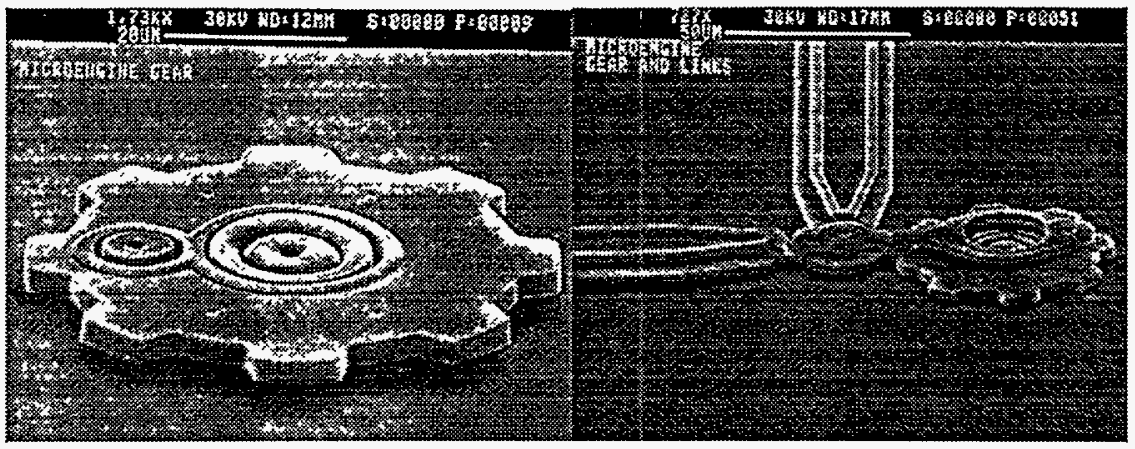

(b)

(c)

Figure 4. a) Simple, yet very useful structures, particularly for sensor applications, can be fabricated using a single level of mechanical polysilicon. b) A double level process produces movable mechanical elements. However, connection to these structures is limited. Here a gear with a central hub attached to the substrate and a free-spinning pin along its radius is shown. However, connection to the radial pin is not possible without a third layer of polysilicon. c) A triple level process allows the fabrication of complex, interconnected, interactive mechanisms with actuators. That is, the gear in Fig. $4 \mathrm{~b}$ is now connected to a linkage element and can be actuated upon by that element.

Although not clearly illustrated in Fig. 4, there is usually an additional polysilicon layer included in these processes. This polysilicon layer does not form mechanical elements, rather, it serves to form voltage reference planes and electrical interconnects. This film is not counted in the reference to single, double, and triple level processes. Figure $4 \mathrm{a}$ illustrates a simple comb drive resonator. Typically, with one level of polysilicon, the structures have restricted movement through elastic members attached to the substrate. Although with a single-level process the degree of mechanical complexity is limited, it can produce very useful and commercially viable devices, particularly in sensor applications. One such example is Analog Device's surface micromachined accelerometer [41]. Extension to a double-level process (Fig. $4 \mathrm{~b}$ ) begins to allow considerably greater mechanical design flexibility, particularly with regard to rotating elements. As seen in Fig. $4 b$, a free-spinning gear attached to the substrate with a freespinning pin at some radius from its center can be produced. However, a third level of polysilicon is needed to fully couple energy to and from this gear. Fig. 4c illustrates this ability to interconnect elements with absolute, hard 
linkages for actuation purposes through the use of three levels. Note also that any or all of the mechanical layers can be made electrically conductive, thus providing additional layers for electrical interconnect or electrodes.

For the purpose of describing the three-level polysilicon process, the electrostatic comb-driven microengine will be referenced since it requires all three levels of mechanical polysilicon for fabrication. Discussion of the operation of the microengine itself is deferred until Section 5.2. The microengine is fully batch-fabricated; the fabrication process does not rely on assembly of separately fabricated piece-parts. By contrast, a similar linkage system which connects two rotary devices together has been demonstrated [42]. In that case, the links and rotary elements were originally fabricated on separate wafers which were then bonded together. The final structures were then realized by dissolution of one of the wafers, and operation of the linkages with manual probe manipulation was reported.

The batch-fabrication of integrated gear-link assemblies by surface micromachining techniques presents several fundamental difficulties. In general, these difficulties are due to the vertical topology introduced by the deposition and etching of the various films used. Link/gear interference, which occurs with normally deposited films used in surface micromachining, has been alleviated by the present microengine design and fabrication process. This interference normally arises when the interconnecting link must pass over the gear edge, or the concentric retaining hub of the gear, as the mechanism moves through one complete rotational cycle.

Using an 8-mask process, the microengine can be produced in a way that avoids these difficulties. Noninterfering rotary motion of the system can be accomplished by a unique positioning and layout of the links, gear hub, and gear during the patterning and etching of these films. Upon final sacrificial etch and release, these considerations assure that full rotation is accomplished without interference.

The microengine is formed using surface micromachining of multiple polysilicon films with intervening sacrificial oxide films. The fabrication of the microengine, including the electrostatic comb-drives, the power output gear, and the interconnecting linkages, requires four depositions of polysilicon. The first of the polysilicon layers serves to provide a voltage reference plane and electrical interconnects, while the remaining three polysilicon layers serve to form the mechanical elements. The electrical polysilicon is referred to as POLY 0 , and the first, second, and third mechanical polysilicon films are referred to as POLY 1, POLY 2, and POLY 3, respectively. All polysilicon depositions are Low Pressure Chemical Vapor Deposited (LPCVD), fine-grained polycrystalline silicon deposited at $580^{\circ} \mathrm{C}$.

To begin, a silicon substrate is coated with dielectric isolation films of LPCVD silicon-rich nitride over thermal oxide as a blanket starting point. The reason for the blanket isolation films is to ensure that proper electrical isolation is achieved between electrically active parts of the microengine structures.

The first patterned layer (which uses mask \#1) is the electrical interconnect and shield polysilicon, POLY 0. The electrostatic comb-drive stator-to-substrate anchor areas and the stiction-reduction dimple molds are patterned into the 
first thick sacrificial glass layer deposited after POLY 0, using masks \#2 and \#3, respectively. The subsequent polysilicon film to be deposited fills in the anchor and mold areas to provide attachment of the structures to the substrate and 'dimples' on the otherwise flat underside of the polysilicon for stiction.reduction.

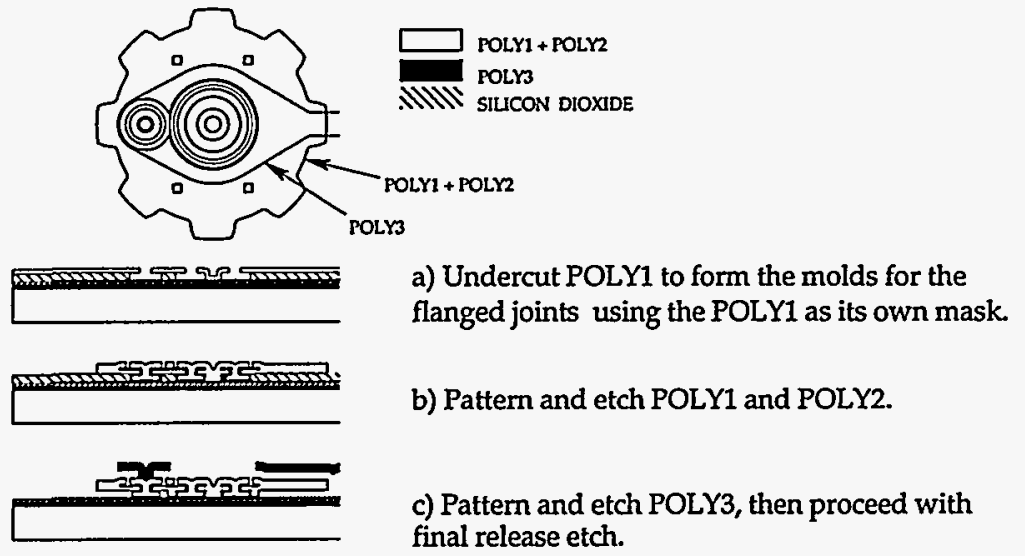

Fig. 5 Schematic cross-sections through essential elements of the gear and joints taken at three stages of device completion.

The comb drives and output gear are constructed from the first and second layers of mechanical polysilicon (POLY 1 and POLY 2), while the X-and Y- interconnecting link is formed from a composition of all three mechanical polysilicon films. The top view (Fig. 5) of the microengine has the polysilicon layers indicated for each of these elements. Sacrificial glass layers are used between the four polysilicon levels.

The flanged restraining hub for the output gear is formed from the POLY 2 deposition with the hub anchor being formed by a process in which the POLY 1 level is deposited and etched with mask \#4 (see Fig. 5). A partial undercut etch of the sacrificial glass under POLY 1 is done to begin to form the basis for the flanged hub. The hub joint and link connections to the comb-drives and the output gear are of the flanged type and are formed by a process similar to that described in reference [43] (see Fig. 5b).

The partial undercut is backfilled by a thin $(\leq 0.5 \mu \mathrm{m})$ oxide deposition to form the spacing between the flange and the gear and link joints. This oxide is patterned by mask \#5 so that it remains only in the joint and bearing areas. At this point, the POLY 2 deposition is done. The polysilicon deposition is conformal, meaning that it uniformly coats any surface, including backfilling the flange undercut. In the areas outside the joints and bearing where the flange spacer oxide was removed, the POLY 2 deposits directly on POLY 1 to form a single layer of polysilicon. This single layer comprises the gear body, parts of the links, and the comb drives. The polysilicon sandwich is patterned and etched using mask \#6 to form the above parts.

This sequence of depositions and critical dimensions outlined in the design rules produces nearly planar surfaces over the gear and joints. This permits non-interference of the gear/link assembly during operation. In addition, a silicon nitride friction-reduction layer is incorporated before the POLY 2 deposition to form a friction-reduction layer on the flanged surfaces. This layer is illustrated as the solid black layer in Fig. 5b-c. 
After the patterning with mask \#6, the second major sacrificial glass is deposited to a thickness on the order of 2 $\mu \mathrm{m}$. Mask \#7 is used to define the anchor areas for POLY 3 to the links and connecting flanged pin joint in the gear. The final POLY 3 layer is deposited, patterned, and etched using mask \#8 to form the final link portions to connect the entire assembly. A cross-section just prior to the final release etch presents an overview of all the polysilicon and sacrificial films used (Fig. 5.b). A final hydrofluoric acid (HF) release etch produces the completed microengine assembly as shown in Fig. 5.c.

At two intermediate steps, namely after the POLY 2 and POLY 3 depositions, suitable post-deposition anneals must be done to assure that the polysilicon mechanical films do not display undesirable internal stress that would distort the structure upon the final release etch.

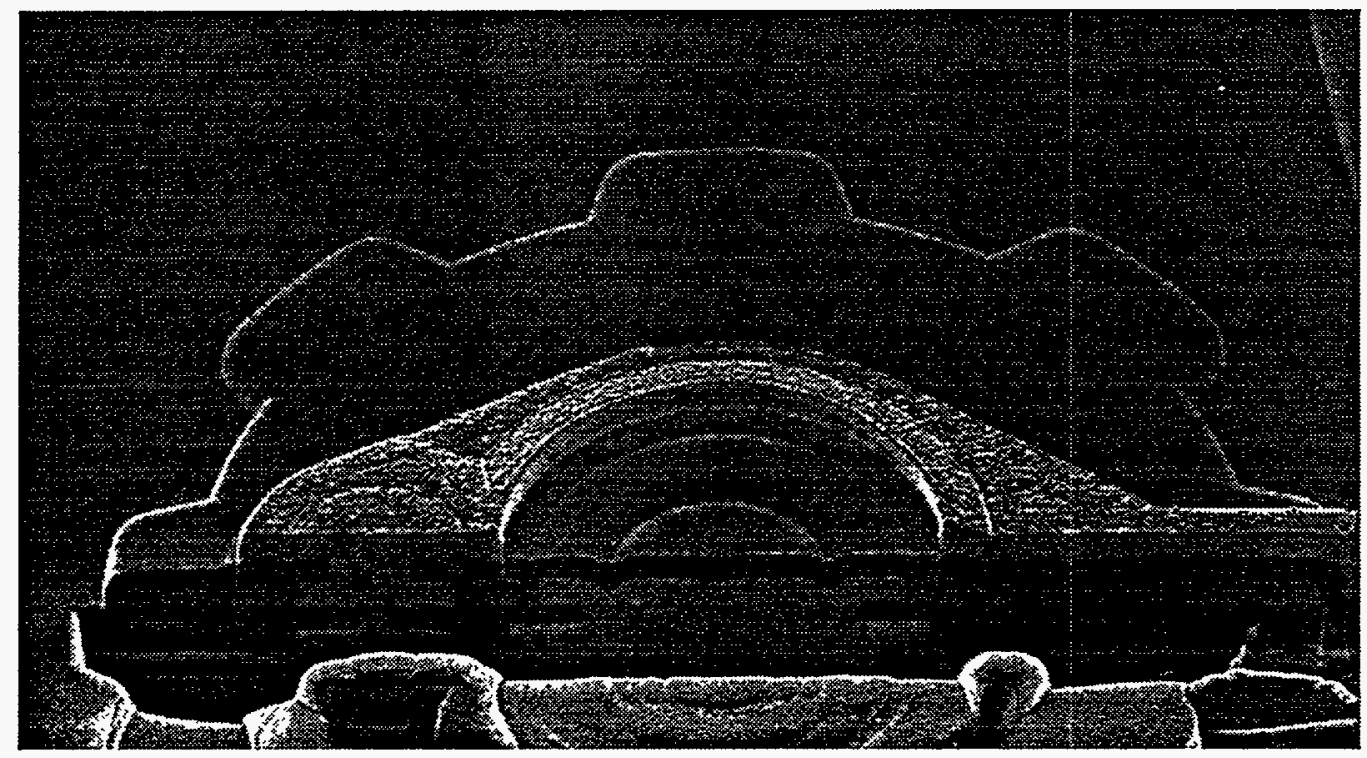

Fig. 6. A FIB micrograph of the cross-section of the gear, joint, and link area just prior to the final HF release etch. Illustrated are the flanged hub attachment to the substrate and the upper link connected to the freespinning pin joint in the gear.

Figure 6, is a focused ion beam (FIB) micrograph of the output-gear and pin-joint cross-section. The crosssection details of the as-fabricated gear/link area are shown in the FIB micrograph image just prior to the final release etch.

\section{MULTI-LEVEL POLYSILICON MICROACTUATORS}

\subsection{Surface Tension Actuator}

Earlier we mentioned that there is often compromise involved in choosing an actuation mechanism. For example, the actuator may be forceful enough but provides inadequate displacement. Several approaches have been tried to overcome one or more of these deficiencies, often in the form of arraying the individual actuator element either in series, for greater displacement [44], or in parallel, for greater force [45]. The development of the planar, liquid-vapor surface tension actuator also stemmed from such a deficiency. The fact that surface tension effects are extremely 
significant at these dimensions has been known for some time [46], and is readily apparent from such an every day observation as a mosquito walking on water.

Using this information, a planar, surface tension (ST) based microactuator was designed and fabricated [47]. This micromechanical, surface tension-driven actuator is capable of relatively large displacement and force values. The basic construct is a hollow tube with a piston actuator inside filled with liquid. The construction lies in the plane of the wafer surface and provides actuation force in that plane. A bubble formed at one end of the tube by a polysilicon microbridge heater can be made to propagate down the tube. The work of Lin, Pisano, and Lee [48,49], and Oh, Seung, and Kwak [50] delves into the details of bubble nucleation and formation on a micro-line heater. Their work offers insight into the operational behavior of the surface tension microactuator. Shown in Figure 7, the meniscus formed captures the end of the piston and carries the piston along the tube as the bubble expands. The ST microengine has been designed, fabricated, and demonstrated to have 20 micrometer displacement and over two orders of magnitude greater force than a similarly configured electrostatic actuator. This mechanism is, on a very basic level, the same concept as a macro-sized steam engine. However, at these dimensions, the effects of liquidvapor surface tension have much greater significance.

The theory developed predicts a maximum force of $1.16 \mu \mathrm{N}$ will be produced by this actuator element due to the meniscus alone, ignoring pressure on the face of the piston. By estimating the bubble pressure, we can predict the relative contributions of the surface tension, i.e. the piston edge force to the force generated by the pressure on the face of the piston. In this example, the surface tension contribution is approximately $60 \%$ of the total force on the piston. The importance of this is that the meniscus is extremely effective at sealing what in effect is a very loose piston in a cylinder. The measured displacement and force response agrees well with the simple model for the system.

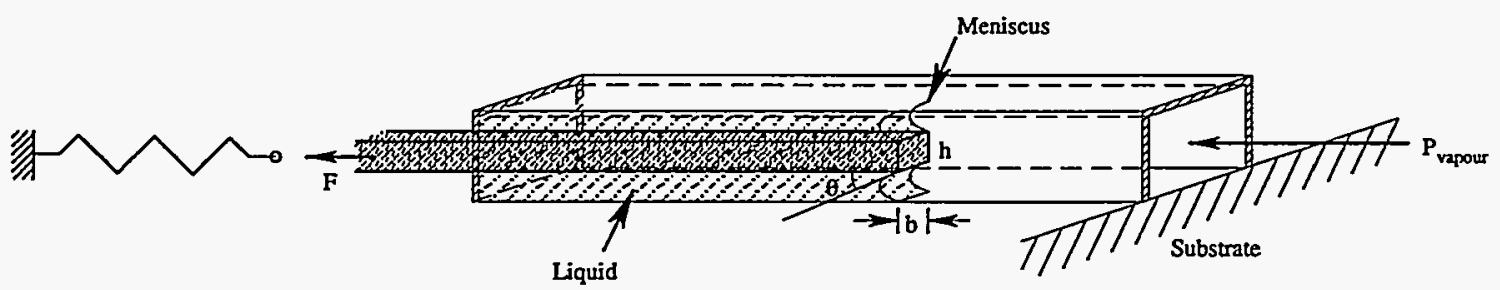

Figure 7. Schematic of microactuator mechanism. A piston is fabricated inside a channel. A heater element, not shown to the right, produces a vapor bubble which propagates to the left inside the channel. The meniscus captures the piston and carries it to the left against the action of an external spring (schematically shown).

A comparative calculation, based on equal cross-sectional area and operating voltage, between this actuator and a comb-type electrostatic actuator provides an illustration of the magnitude of the forces generated by surface tension. The electrostatic calculation was for one comb finger actuated at 20 volts to produce $3.5 \mathrm{nN}$ versus the surface tension actuator force of $0.58 \mu \mathrm{N}$ on a $2 \mu \mathrm{m}$ by $2 \mu \mathrm{m}$ cross-section. This corresponds to a ratio of 164 for the surface tension force to the electrostatic force. 
Extending the schematic of Figure 7, a practical experimental design layout is shown in Figure 8. The piston element is attached to a folded spring assembly which provides the means of determining the actuation force. For this design, the spring constant is $0.039 \mu \mathrm{N} / \mu \mathrm{m}$. Alongside the piston is a vernier scale to measure the piston displacement. Two contact pads are connected to a polysilicon-bridge heater element. The piston element, springs, and polysilicon-bridge are formed from the first polysilicon layer. A second polysilicon layer, separated from the first by a sacrificial oxide, is the rectangular area overlaying most of the piston and the polysilicon-bridge heater as seen in the SEM micrograph of Figure 9. This cover polysilicon partially encapsulates the piston and heater forming channels in which the piston and heater bridge reside. The basic requirement is a 2-level polysilicon process capable of creating a microstructure within a microstructure.

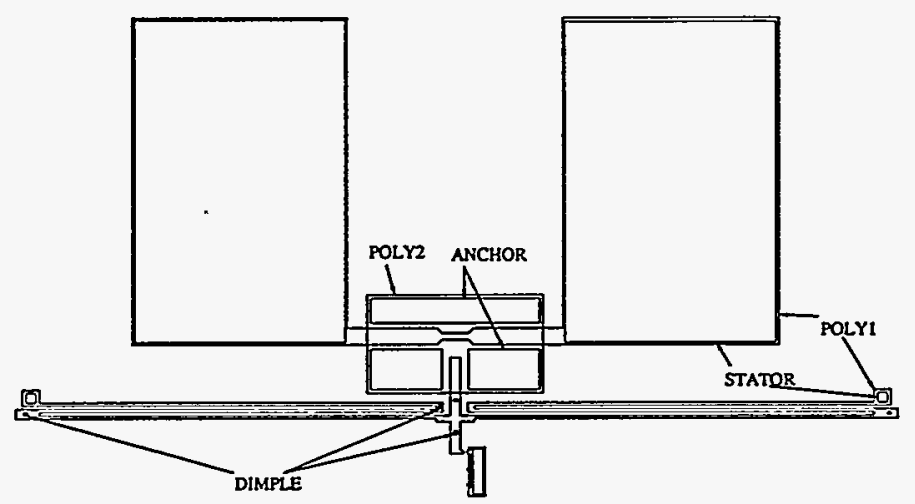

Figure 8. Top view of actuator layout. POLY1 forms the piston, heater, and springs; while POLY2 forms the cover for the 'cylinder'. STATOR and ANCHOR provide the areas for attachment of POLY1 and POLY2 to the substrate. (note: not drawn to scale)

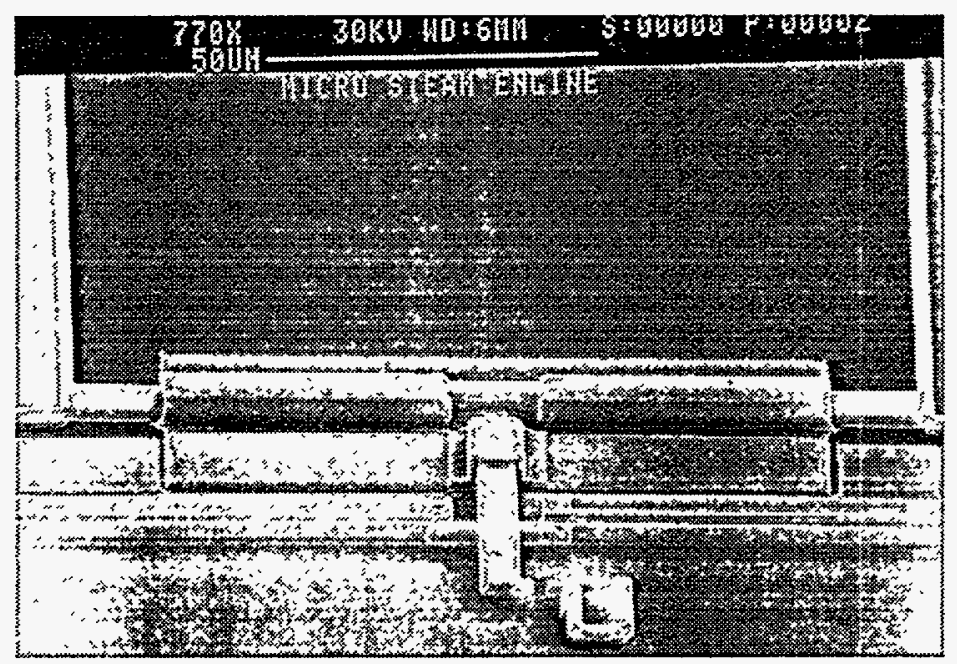

Figure 9. SEM micrograph of a fully functional surface tension actuator. The encapsulated microbridge heater is seen in the background between the contact pads. The piston is supported by two folded beam springs anchored to the substrate outside the view of the SEM. Piston dimensions are $2 \mu \mathrm{m}$ thickness, $6 \mu \mathrm{m}$ width, and measurable displacement is designed to be $10 \mu \mathrm{m}$.

With DI water as the working fluid, we have demonstrated experimentally that the piston can be thrust completely out of the cavity by the bubble propagating down the tube. The maximum force generated is comparable to the force estimated by the simple model. Controlled movement, in both directions, has also been demonstrated. 


\subsection{Electrostatic Microengine}

In a variety of cases, it would be desirable to have a microscopic power source capable of supplying rotating mechanical motion to operate other micromechanisms, i.e., the equivalent, generic function of a macro electric motor. In the microdomain, such a microengine would serve as a general drive and power source to provide force and torque to drive micromechanisms. Micromotors previously demonstrated $[8,51,52]$ might be used if a means for power takeoff can be demonstrated. However, we have taken the alternative approach of adapting an array of linear electrostatic comb actuators [11] to drive a rotating output gear [3]. It is important to note that other types of linear actuators, e.g., the ST microactuator, can also be used if they provide sufficient displacement and force. In fact, it would be desirable to have a more compact linear actuator design to conserve chip area.
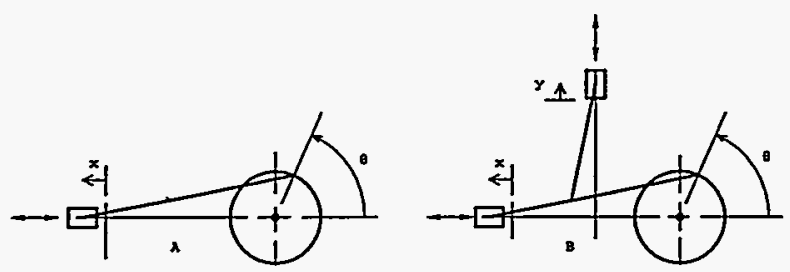

Fig. 10. Microengine schematic illustrating the principle of operation.

Fig. 10A illustrates the arrangement required to convert motion from a linear actuator into circular motion in the form of a rotating output element, e.g. the equivalent to a piston, connecting rod, and crankshaft in an internal combustion engine. The particular arrangement shown suffers from the problem of not delivering torque at $\theta=0$ and $180^{\circ}$. This situation is analogous to that of a single piston engine. To remedy the problem, a flywheel is employed to maintain continuous motion. The concept of a flywheel can also be applied to the microengine; however, inertial effects are not useful during starting or at low speeds.

We have eliminated this problem by introducing another drive linkage oriented $90^{\circ}$ to the original linkage, shown in Fig. 10B. This second drive linkage, driven by another linear actuator, allows positive torque to be supplied to the output element throughout $360^{\circ}$ of rotation. The second linear actuator must be operated $90^{\circ}$ out of phase with the first actuator to produce synchronized motion of the output element; which, in this case, is a gear. The direction of rotation of the output gear is controlled by either leading or lagging the input of the second actuator.

Fig. 11 illustrates the microengine arrangement with comb-drive actuators connected to the output gear by linkages. The linkages are connected to the actuators and output gear through pin joints that allow relative motion. The locations of the pin joints in Fig. 10B can be used as a reference to locate the pin joints in Fig. 11. The horizontal connecting link, also called the $\mathrm{X}$ drive link, is attached to the output gear through a pin joint at a radius of 17 microns relative to the center of the output gear. Fig. 11 shows this arrangement at $\theta=0^{\circ}$, which is in the "as fabricated" position. Figure 12 is a scanning electron micrograph of the output gear and links in the released, as-fabricated position. Tests on the microengine demonstrate that it can rotate in either direction, operate from quasi-static to 
hundreds of thousands of revolutions per minute, and operate for extended periods of time. Greater detail on the microengine is published elsewhere [53].

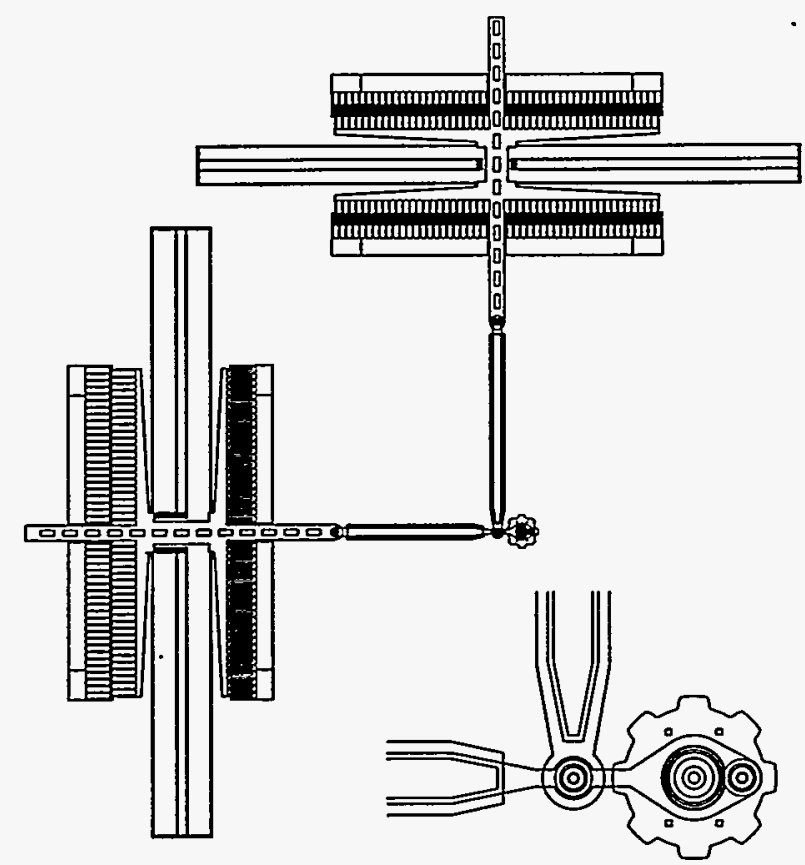

Fig. 11. Schematic drawing of the microengine relevant to actual physical layout of the device. Note: not shown is the second comb drive in series with those shown.

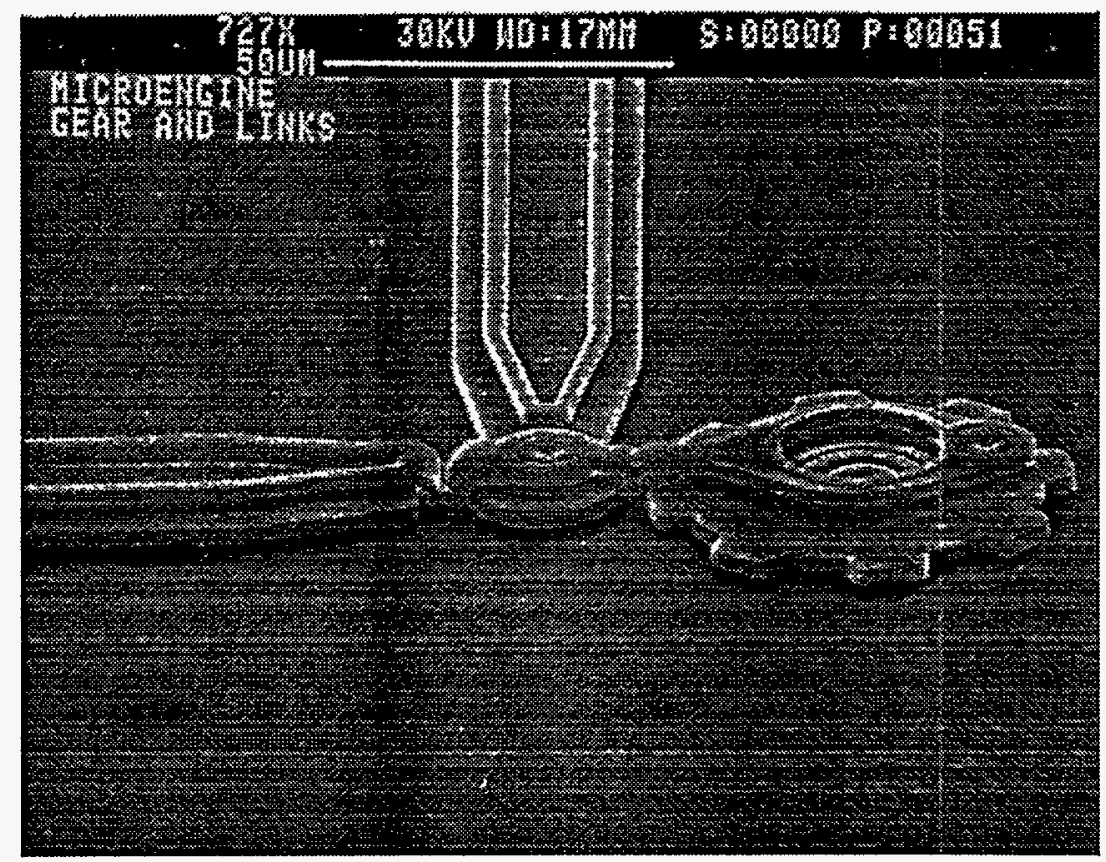

Fig. 12 SEM perspective view of the complete, released gear/link elements of the microengine. The gear shown has a diameter of approximately $50 \mu \mathrm{m}$. The gear thickness is $2.5 \mu \mathrm{m}$. 


\section{CONCLUSION}

While there are a myriad of types of microactuators [9], we have elected to discuss aspects of electrostatic actuators, in particular, because of their compatibility with IC-based surface micromachining fabrication processes. Simple electrostatic actuators are useful for positioning of optical devices if their required motions are small enough to permit the use of flexures such as deformed cantilevers or membranes. These devices typically require no more than one or two levels of construction polysilicon for their fabrication. More complex devices such as the microengine described here require at least three levels of construction polysilicon and are in the category of devices capable of producing infinitely large motions. This type of device will also be used for positioning applications but with much greater capabilities due to the arbitrary motions the device can produce. Micromotors [8] are intermediate and require two levels of construction polysilicon.

Fundamental electrostatic actuation principles were first covered and then related to various efforts reported in the literature (see Table 1) pertaining to optical applications. The fabrication process required to move to complex devices was outlined and compared to processing used to fabricate simpler devices. This three-level process, which consists of three independent construction layers of polysilicon, allows much greater design flexibility and removes several constraints in mechanical design, particularly for microactuators. The application of the three-level process to the microengine was then described. Complex devices, such as the microengine, are now ready to drive a great variety of optical devices with greater latitude than previously demonstrated. The recent literature and the presented work on microactuators clearly indicates that microactuation is beginning to break free of many of its limitations and is starting to surface in many applications. In particular, various types of optical switching functions will be excellent candidates for application of these more complex actuators. We can expect to see this continuing evolution of capability driven by compelling applications in the optics arena.

\section{ACKNOWLEDGMENTS}

This work performed at Sandia National Laboratories supported by the U. S. Department of Energy under contract DE-AC04-94AL85000.

\section{REFERENCES}

1 M. Mehregany, "An overview of microelectromechanical systems," Proc. SPIE, Vol. 1793, Integrated Optics and Microstructures, pp. 2-11, 1992.

$2 \quad$ R. S. Muller, "Microdynamics," Sensors and Actuators, A21-A23, pp. 1-8, 1990.

3 E. J. Garcia and J. J. Sniegowski, "The design and modelling of a comb-drive-based microengine for mechanism drive applications", Proceedings of the 7th International Conference on Solid-State Sensors and Actuators (Transducers '93), Yokohama, Japan. June 7-10, pp 763-766, 1993.

4 R. T. Howe, "Surface micromachining for microsensors and microactuators," J. Vac. Sci. Techn. B, vol. 6, no. 6, pp. 18091813, Nov/Dec 1988.

5 D. L. Kendall and G. R. de Guel, "Orientations of the third kind : The coming of age of (110) silicon," Proc. of the Workshop on Micropackaging of Transducers, Cleveland, OH, pp. 141-162, Nov. 1984. 

Chapman, "Deep X-ray and UV lithographies for micromechanics," Technical Digest Solid-State Sensor and Actuator Workshop, Hilton Head Is., SC, pp. 118-122, June 1990.

7 H. Toshiyoshi, H. Fujita, T. Kawai, and T. Ueda, "Piezoelectrically operated actuators by quartz micromachining for optical applications," Proc. of Micro Electro Mechanical Systems, Fort Lauderdale, FL, pp. 133-138, Feb. 1993. L. -S. Fan, Y. -C. Tai, and R. S. Muller, "IC-processed electrostatic micromotors," Sensors and Actuators vol. 20, no. 1\&2, pp. 41-47, 1989.

9 H. Fujita and K. J. Gabriel, "New opportunities for micro actuators," Technical Digest, 6th Int. Conf. Solid-State Sensors and Actuators, San Francisco, CA, pp. 14-20, June 1991.

10 V. P. Jaecklin, C. Linder, N. F. DeRooij, J.-M Moret, and R. Vuilleumier, "Line-addressable torsional micromirrors for light modulator arrays," Sensors and Actuators A41-42, pp. 324-329, 1994.

11 W. C. Tang, T-C. H. Nguyen, and R. T. Howe, "Laterally driven polysilicon resonant microstructures," Sensors and Actuators, vol. 20, 1989, pp. 25-32.

12 W. A. Johnson and L. K. Warne, "Electrophysics of micromechanical comb actuators," accepted for publication in the Journal of MicroElectroMechanical Systems (JMEMS), 1995.

13 W. C. Tang, M. G. Lim, and R. T. Howe, "Electrostatically balanced comb drive for controlled levitation," Technical Digest Solid-State Sensor and Actuator Workshop, Hilton Head Is., SC, pp. 23-27, June 1990.

14 R. M. Boysel, T. G. McDonald, G. A. Magel, G. C. Smith, and J. L. Leonard, "Integration of Deformable Mirror Devices with optical fibers and waveguides," Proc. SPIE, Vol. 1793, pp. 34-39, 1992.

15 N. A. Riza, "Micromechanical fiber-optic switches for optical networks," Proc. SPIE, Vol. 1793, pp. 108-113, 1992.

16 J. Mohr, M. Kohl, and W. Menz, "Micro optical switching by electrostatic linear actuators with large displacements," Technical Digest, 7th Int. Conf. Solid-State Sensors and Actuators, Yokohama, Japan, pp. 120-123, June 1993.

17 R. B. Apte, F. S. A. Sandejas, W. C. Banyai, and D. M. Bloom, "Deformable grating light valves for high resolution displays," Technical Digest Solid-State Sensor and Actuator Workshop, Hilton Head Is., SC, pp. 1-6, June 1994.

18 Y. W. Kim, M. G. Allen, and N. F. Hartman, "Micromechanically based integrated optic modulators and switches," Proc. SPIE, Vol. 1793, pp. 183-189, 1992.

19 R. Jebens, W. Trimmer, and J. Walker, "Micro actuators for aligning optical fibers," Proc. of Micro Electro Mechanical Systems, Salt Lake City, UT, pp. 35-39, Feb. 1989.

20 Y. Kikuya, M. Hirano, K. Koyabu, and F. Ohira, "Micro alignment machine for optical coupling," Proc. of Micro Electro Mechanical Systems, Fort Lauderdale, FL, pp. 36-41, Feb. 1993.

21 S. Nagaoka, "Micro-magnetic alloy tubes for switching and splicing single-mode fibers," Proc. of Micro Electro . Mechanical Systems, Nara, Japan, pp. 86-91, Feb. 1991.

R. Jebens, W. Trimmer, and J. Walker, "Microactuators for aligning optical fibers," Sensors and Actuators 20, pp. 65-73, 1989.

23 J. B. Sampsell, "The Digital Mirror Device and its application to projection displays," Technical Digest, 7th Int. Conf. Solid-State Sensors and Actuators, Yokohama, Japan, pp. 24-27, June 1993.

24 P. Pliska and W. Lukosz, "Electrostatically actuated integrated optical nanomechanical devices," Proc. SPIE, Vol. 1793, pp. 259-272, 1992.

25 M. Fischer, H. Graef, and W. von Munch, "Electrostatically deflectable polysilicon torsional mirrors," Sensors and Actuators A44, pp. 83-89, 1994.

26 V. P. Jaecklin, C. Linder, N. F. DeRooij, J.-M Moret, and R. Vuilleumier, "Line-addressable torsional micromirrors for light modulator arrays," Sensors and Actuators A41-42, pp. 324-329, 1994.

27 V. P. Jaecklin, C. Linder, J. Brugger, J.-M. Moret, R. Vuilleumier, and N. F. de Rooij, "Mechanical and optical properties of surface micromachined torsional mirrors in silicon, polysilicon and aluminum," Technical Digest, 7th Int. Conf. SolidState Sensors and Actuators, Yokohama, Japan, pp. 958-961, June 1993.

28 E. Obermeier, J. Lin, and V. Schlichting, "Design and Fabrication of an electrostatically driven micro-shutter," Technical Digest, 7th Int. Conf. Solid-State Sensors and Actuators, Yokohama, Japan, pp. 132-135, June 1993.

29 M. Hisanaga, T. Koumura, and T. Hattori, "Fabrication of 3-dimensionally shaped Si diaphragm dynamic focusing mirror," Proc. of Micro Electro Mechanical Systems, Fort Lauderdale, FL, pp. 30-35, Feb. 1993.

30 J. H. Jerman, D. J. Clift, and S. R. Mallinson, "A miniature Fabry-Perot interferometer with a corrugated silicon diaphragm support," Technical Digest Solid-State Sensor and Actuator Workshop, Hilton Head Is., SC, pp. 140-144, June 1990.

31 K. Deng, H. Miyajima, V. R. Dhuler, M. Mehregany, S. W. smith, F. L. Merat, and S. Furukawa, "The development of polysilicon micromotors for optical scanning applications," Technical Digest Solid-State Sensor and Actuator Workshop, Hilton Head Is., SC, pp. 234-238, June 1994.

32 H. Miyajima, K. Deng, M. Mehregany, F. L. Merat, and S. Furukawa, "Fabrication of polygon mirror microscanner by surface micromachining," Proc. SPIE, Vol. 2291, pp. 62-73, 1994. 
P. Y. Chen and R. S. Muller, "Microchopper-modulated IR microlamp," Technical Digest Solid-State Sensor and Actuator Workshop, Hilton Head Is., SC, pp. 239-242, June 1994.

O. Tabata, R. Asahi, N. Fujitsuka, M. Kimura, and S. Sugiyama, "Electrostatic driven optical chopper using SOI wafer," Technical Digest, 7th Int. Conf. Solid-State Sensors and Actuators, Yokohama, Japan, pp. 124-127, June 1993.

H. Toshiyoshi, H. Fujita, T. Kawai, and T. Ueda, "A piezoelectrically operated optical chopper by quartz micromachining," Technical Digest, 7th Int. Conf. Solid-State Sensors and Actuators, Yokohama, Japan, pp. 128-131, June 1993.

S. T. Wilkinson, Y. W. Kim, M. G. Allen, and N. M. Jokerst, "Integration of thin-film compound semiconductor photonic devices onto micromachined movable platforms," Technical Digest, 7th Int. Conf. Solid-State Sensors and Actuators, Yokohama, Japan, pp. 148-151, June 1993.

L. J. Hornbeck, "Deformable-mirror spatial light modulators," Proc. SPIE Vol. 1150, pp. 86-102, 1989.

H. C. Nathanson, W. E. Newell, R. A. Wickstrom, and J. R. Davis, "The Resonant Gate Transistor," IEEE Trans. Electron Devices, Vol. ED-14, pp. 117-133, March 1967. SCIENCE AND TECHNOLOGY, Vol. 103, No. 6, pp. 1420-1423, June 1983.

L-S. Fan, Y-C. Tai and R. S. Muller, "Integrated movable micromechanical structures for sensors and actuators", IEEE Trans. Electron Devices, vol. 35, no. 6, pp. 724-730, June 1988. "Monolithic accelerometer with signal conditioning," Analog Devices, ADXIL50 Technical report. Y. Gianchandani and K Najafi, "Batch Fabrication and Assembly of Micromotor-Driven Mechanisms with Multi-Level Linkages", micro Electro Mechanical Systems '92, Travemunde (Germany), pp. 141-146, Feb. 4-7, 1992. Trans. Electron Devices, vol. 35, no. 6, June 1988, pp. 724-730. L. -Y. Chen, E. J. P. Santos, and N. C. MacDonald, "Serial-parallel isolated capacitive microactuators," Technical Digest, 7th Int. Conf. Solid-State Sensors and Actuators, Yokohama, Japan, pp. 148-151, June 1993. L.-S. Fan, S. J. Woodman, R. C. Moore, L. Crawforth, T. C. Reiley, and M. A. Moser, "Batch-fabricated area-efficient milli-actuators," Technical Digest Solid-State Sensor and Actuator Workshop, Hilton Head Is., SC, pp. 38-42, June 1994. H. Guckel, J. J. Sniegowski, T. R. Christenson, S. Mohney, and, T. F. Kelley, "Fabrication of micromechanical devices from polysilicon films with smooth surfaces," Sensors and Actuators, vol. 20, pp. 117-122, 1989. J. J. Sniegowski, "A microactuation mechanism based on liquid-vapor surface tension," Abstracts of Late News Papers of the 7th International Conference on Solid-State Sensors and Actuators, TRANSDUCERS '93, Yokohama, Japan, p. 12, June 1993.

L. Lin, A. P. Pisano, and A. P. Lee, "Microbubble powered actuator," Transducers' 91, Sixth International Conference on Solid-State Sensors and Actuators, San Francisco, USA, June 1991, 1041-1044. L. Lin and A. P. Pisano, "Bubble forming on a micro line heater," DSC-Vol. 32, Micromechanical Sensors, Actuators, and Systems, ASME 1991, 147-163.

S.-D. Oh, S.-S. Seung, and H.-Y. Kwak, "A model of bubble nucleation on a micro line heater," DSC-Vol. 40, Micromechanical Systems, ASME 1992, 313-328.

51 Y-C. Tai and R. S. Muller, "IC-processed electrostatic synchronous micromotors", Sensors and Actuators, Vol. 20, 1989, pp. 49-55.

M. Mehregany, et. al., "Operation of microfabricated harmonic and ordinary side-drive motors", Proc. of Micro Electro Mechanical Systems, Napa Valley, CA, Feb. 1990, pp. 1-8. E. J. Garcia and J. J. Sniegowski, "Surface micromachined microengine," submitted to Sensors and Actuators 1995. 


\section{DISCLAIMER}

This report was prepared as an account of work sponsored by an agency of the United States Government. Neither the United States Government nor any agency thereof, nor any of their employees, makes any warranty, express or implied, or assumes any legal liability or responsibility for the accuracy, completeness, or usefulness of any information, apparatus, product, or process disclosed, or represents that its use would not infringe privately owned rights. Reference herein to any specific commercial product, process, or service by trade name, trademark, manufacturer, or otherwise does not necessarily constitute or imply its endorsement, recommendation, or favoring by the United States Government or any agency thereof. The views and opinions of authors expressed herein do not necessarily state or reflect those of the United States Government or any agency thereof. 